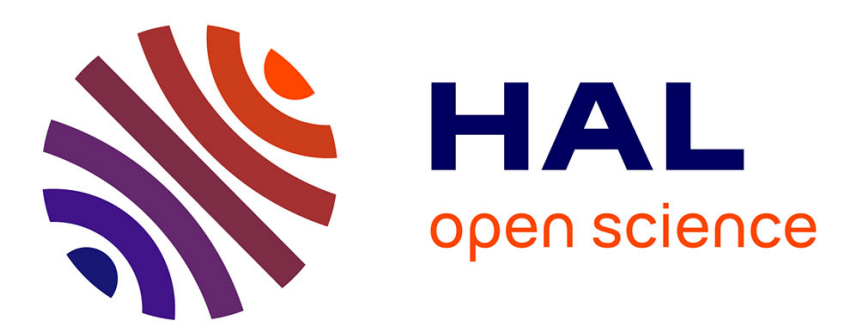

\title{
Influence of interaural time differences on loudness for low-frequency pure tones at varying signal and noise levels
}

\author{
Gauthier Berthomieu, Vincent Koehl, Mathieu Paquier
}

\section{To cite this version:}

Gauthier Berthomieu, Vincent Koehl, Mathieu Paquier. Influence of interaural time differences on loudness for low-frequency pure tones at varying signal and noise levels. Proceedings of meetings on acoustics, 2017, 30 (1), pp.050004. 10.1121/2.0000553 . hal-01580000

\section{HAL Id: hal-01580000 \\ https://hal.univ-brest.fr/hal-01580000}

Submitted on 1 Sep 2017

HAL is a multi-disciplinary open access archive for the deposit and dissemination of scientific research documents, whether they are published or not. The documents may come from teaching and research institutions in France or abroad, or from public or private research centers.
L'archive ouverte pluridisciplinaire HAL, est destinée au dépôt et à la diffusion de documents scientifiques de niveau recherche, publiés ou non, émanant des établissements d'enseignement et de recherche français ou étrangers, des laboratoires publics ou privés. 


\section{Proceedings of Meetings on Acoustics}

Volume 30

http://acousticalsociety.org/

\section{Acoustics`17 Boston}

173rd Meeting of Acoustical Society of America and 8th Forum Acusticum

Boston, Massachusetts

25-29 June 2017

\section{Psychological and Physiological Acoustics: Paper 5aPPb1}

\section{Influence of interaural time differences on loudness for low-frequency pure tones at varying signal and noise levels}

Gauthier Berthomieu, Vincent Koehl and Mathieu Paquier

Lab-STICC, University of Brest, Brest, Bretagne, 29200, FRANCE; gauthier.berthomieu@univ-brest.fr, vincent.koehl@univ-brest.fr,mathieu.paquier@univ-brest.fr

Directional loudness sensitivity, which is generally accounted for by at-ear pressure modifications because of the perturbation of the sound field by the head, has been reported to occur at $400 \mathrm{~Hz}$ where shadowing effects are usually considered small. Then, an effect of the interaural time difference (ITD) on loudness has been observed for pure tones below $500 \mathrm{~Hz}$. The latter was rather small but still significant, contributing to directional loudness sensitivity. In addition, it has been shown that the effect of ITD on loudness was caused by the ITD itself and not by its related localization. As this effect appeared significant at low level only (40 phon), it was hypothesized that ITD could help separate the signal from the internal noise and enhance its loudness. The aim of the present study is to confirm this hypothesis by observing the effect of ITD on the loudness of low-frequency pure tones $(100 \mathrm{and} 200 \mathrm{~Hz})$ for various signal-to-noise ratios. The signal level was varied from 30 to 90 phon and the noise could be internal only or external also. The effect of ITD appeared significant at low levels or for small signal-to-noise ratios.

Published by the Acoustical Society of America 


\section{INTRODUCTION}

\section{A. DIRECTIONAL LOUDNESS}

The localization of a sound source may affect its loudness. This effect has been explored on narrowband noises (Robinson and Whittle, 1960; Sivonen and Ellermeier, 2006) presented through loudspeakers located at several positions around the listener. The latter had to match the loudness of a test sound that was emitted from a given direction to that of a reference sound emitted from a reference direction. These studies have highlighted an effect of the direction of the sound on its loudness, and more precisely that narrowband sounds emitted by lateral sources (i.e., located at one side of the head) were perceived louder than if they were emitted by frontal sources (i.e., located in front of the head). This effect, known as directional loudness, is highly accounted for by the physical effects of the human body on the stimulation. Depending on the source localization, the sound pressure at each of the two ears will be differently modified, and the loudness that results from a binaural summation process will be dependent on the localization of the source. At-ear pressure modifications are included in binaural loudness models as sound pressure levels are needed at both ears in order to take binaural phenomena such as inhibition (the signal at one ear may inhibit the internal response to a signal at the other ear) into account (Moore and Glasberg, 2007; Moore et al., 2016).

Sivonen and Ellermeier (2006) observed an effect of the source azimuth on loudness for narrow-band noises with a center frequency of $400 \mathrm{~Hz}$, where the acoustic shadow of the listener's head is considered small (Moore, 2012). According to this, the modification of the at-ear sound pressure level, which is small for a distant source, couldn't fully account for the observed directional loudness. Furthermore, Moore and Glasberg (2007) used Sivonen and Ellermeier's data at $5 \mathrm{kHz}$ as an input of their model, and found that the latter underestimates the directional loudness sensitivity compared to the experimental results, suggesting that modifications of sound pressure aren't the only element to take into account for computing binaural loudness summation.

\section{B. INFLUENCE OF INTERAURAL TIME DIFFERENCES ON LOUDNESS}

When a sound comes from the side of the head, it reaches one ear before the other. This interaural time difference (ITD) involves an interaural phase difference (IPD) for pure tones, and both can be used as a localization cue for low-frequency tones (Moore, 2012). As loudness variations were noticed at relatively low frequencies, several studies have investigated the influence of ITDs/IPDs on loudness. Koehl and Paquier (2015) explored the dependence of loudness on ITD highlighted by Mulligan et al. (1985) for binaural pure tones. In their study, they used an adaptive forced-choice procedure to compare the loudness of 14 headphone-generated pure tones including two levels (40 and 70 phon), two frequencies (200 and $400 \mathrm{~Hz})$ and seven ITDs $(0, \pm 386, \pm 669$ and $\pm 772 \mu \mathrm{s})$. They found out that for both frequencies and only for low-level stimuli, the higher was the ITD, the louder the sound was perceived. As high-level processes can affect loudness, like the loudness constancy occurring with the perception of distance (Zahorik and Wightman, 2001), the authors wondered if the loudness variations they observed were accounted for by the ITD itself or by the localization process. Koehl et al. (2015) studied the loudness of tones comprising both ITD and interaural level differences (ILD) at the same time. These localization cues could be congruent (i.e., leading to the same side) or opposite (leading to opposite sides). They highlighted that the loudness was affected in the same way whether these two localization cues were congruent or opposite. Therefore, the hypothesis that the effect of the ITD on loudness is due to the time difference itself (and not the corresponding localization sensation) was supported.

The authors also investigated the effect of the ITD at hearing threshold. No single effect of the ITD on loudness proved to be significant for the four tested ITDs (Koehl et al., 2015). 


\section{FIRST EXPERIMENT}

As the effect of the ITD on loudness was significant for low-frequency, low-level pure tones, a first experiment was designed in order to highlight the evolution of this effect over a large range of levels for two low-frequency pure tones. The stimuli were presented via headphones in an audiometric booth. Two frequencies (100 and $200 \mathrm{~Hz}$ ) and seven levels were investigated, ranging from 30 to 90 phon.

\section{MASKING LEVEL DIFFERENCES AND SUPRATHRESHOLD LOUDNESS}

It is known that the interaural phase has an effect on binaural unmasking. Hirsh (1948) highlighted that the detection threshold of a sound was lower in an antiphasic condition (i.e., the interaural correlations of the signal and the noise are opposite) than in an homophasic condition (i.e., the interaural correlations of the signal and the noise are the same). These threshold differences are known as masking level differences (MLD). When the signal-to-noise ratio increases, these MLDs result in loudness disparities between homophasic and antiphasic stimuli. Townsend and Goldstein (1972) reported that at $250 \mathrm{~Hz}$, differences in noise and signal correlations affect loudness even at $20 \mathrm{~dB}$ SL (i.e., $20 \mathrm{~dB}$ above the signal masked threshold), the highest level the authors tested. Soderquist and Shilling (1990) reported that differences in noise and signal correlations don't affect loudness anymore above $10 \mathrm{~dB}$ SL at $200 \mathrm{~Hz}$, whereas Zwicker and Henning (1991) highlighted that at $250 \mathrm{~Hz}$ the effect of interaural phase on loudness remains measurable up to $30-40 \mathrm{~dB}$ SL. As the effect of ITD on loudness observed in the first experiment tends to occur at low levels only, it has been hypothesized that it might be accounted for by a lower-level noise, that is to say the internal noise. The latter corresponds to the noise in which the masking threshold equates to the hearing threshold (Bernstein and Trahiotis, 2008; Diercks and Jeffress, 1962). As the size of the MLD decreases with decreasing the masker level (Hirsh, 1948) and the interaural correlation of the masking noise (Robinson and Jeffress, 1963), it has been assumed that at low level the masking noise merges with the internal noise, decreasing the interaural correlation of the resulting noise (Yost, 1988). This assumption is based on an interaurally uncorrelated (or at least partially uncorrelated) internal noise, but the exact nature of the latter isn't fully defined so far. Some authors report a small positive interaural correlation (Diercks and Jeffress, 1962) while others report a small negative interaural correlation (Bernstein and Trahiotis, 2008) depending on the frequencies they investigated.

\section{E. SECOND EXPERIMENT}

As previous experiments reported a significant effect on the loudness far above the hearing threshold (ISO 389-7), a second experiment was designed in order to check if such a low-level noise could affect the loudness of these medium-level stimuli. This second experiment was similar to the first one except that an external noise was added. In this experiment, only $200 \mathrm{~Hz}$ pure tones were investigated at levels ranging from 30 to 80 phon, and the external noise spectrum level was adjusted in order to obtain 10 or 20 phon noises.

\section{EXPERIMENT I}

This experiment consisted of matching the loudness of test pure tones that could be diotic (i.e., a simultaneous presentation of the same sound to the two ears) or dichotic (i.e., the stimuli at one or the other ear is different, due to an ITD in the present study) on reference pure tones (diotic) of the same frequency at different reference levels in order to investigate the effect of ITD on loudness. 


\begin{tabular}{|c||c||c|}
\hline & $100 \mathrm{~Hz}$ & $200 \mathrm{~Hz}$ \\
\hline \hline 30 phon & $56.7609 \mathrm{~dB}$ & $44.7777 \mathrm{~dB}$ \\
\hline 40 phon & $64.3711 \mathrm{~dB}$ & $53.4087 \mathrm{~dB}$ \\
\hline 50 phon & $71.6095 \mathrm{~dB}$ & $61.7210 \mathrm{~dB}$ \\
\hline 60 phon & $78.6546 \mathrm{~dB}$ & $69.8643 \mathrm{~dB}$ \\
\hline 70 phon & $85.5957 \mathrm{~dB}$ & $77.9158 \mathrm{~dB}$ \\
\hline 80 phon & $92.4797 \mathrm{~dB}$ & $85.9166 \mathrm{~dB}$ \\
\hline 90 phon & $99.3320 \mathrm{~dB}$ & $93.8891 \mathrm{~dB}$ \\
\hline
\end{tabular}

Table 1: SPL/phon equivalences for each stimuli

\section{A. STIMULI}

As the effect of the ITD on loudness was more significant at $200 \mathrm{~Hz}$ than at $400 \mathrm{~Hz}$ (Koehl and Paquier, 2015), two frequencies were investigated in this experiment: $200 \mathrm{~Hz}$ and $100 \mathrm{~Hz}$. The latter had been chosen in order to check if the effect was higher, the lower the frequency was. The ITD value of the dichotic stimuli to be matched was fixed at $772 \mu$ s (i.e., the sound was presented at one ear $772 \mu$ s before the other). This value was derived from Kuhn's low-frequency model (Kuhn, 1977), which is valid below $500 \mathrm{~Hz}$ :

$$
\operatorname{ITD}\left(\theta_{\text {inc }}\right)=\frac{3 \mathrm{a}}{\mathrm{c}_{0}} \cdot \sin \theta_{\text {inc }}
$$

where $a=8.75 \mathrm{~cm}$ is the average radius of the head, $c_{0}=340 \mathrm{~m} / \mathrm{s}$ the speed of sound in the air and $\theta_{i n c}$ the azimuth of the source, with $\theta_{i n c}=90^{\circ}$ for a source located on the interaural axis. The dichotic sounds were always presented to the left ear first, since the effect of the ITD on loudness was revealed to be symmetrical by Koehl and Paquier (2015). Stimuli with ITDs of 0 or $772 \mu$ s (corresponding to an incidence angle of 0 or $90^{\circ}$, respectively) were to be matched to diotic references (i.e., with no ITD) whose levels were fixed at $30,40,50,60,70,80$ or 90 phon. The corresponding levels at 100 and $200 \mathrm{~Hz}$ were computed according to ISO 226 standard (see Table 1). They were fixed by placing the headphones (Sennheiser HD 650, circumaural, open) on a dummy head (Neumann KU100), adjusted using a sound calibrator (Brüel \& Kjær Type 4231) at $1 \mathrm{kHz}$. The duration of each stimulus was $1.6 \mathrm{~s}$, smoothed by onset and offset ramps of $100 \mathrm{~ms}$ according to the stimuli used by Koehl and Paquier (2015).

\section{B. PROCEDURE}

Twenty-two subjects ( 8 women and 14 men, aged 20 to 25 years) took part in the experiment and were remunerated for their participation. They had normal hearing thresholds ( $\leq 10 \mathrm{~dB} \mathrm{HL})$ based on an audiogram taken in the month preceding this experiment. None of them had experience in laboratory listening tests.

The equal-loudness levels were obtained using a two-interval, two-alternative, forced choice paradigm (2I2AFC), following a 1-up 1-down rule (Levitt, 1971). This procedure was the same as that used in previous studies (Koehl and Paquier, 2015; Koehl et al., 2015). In each trial, a test sound (whose ITD was either 0 or $772 \mu \mathrm{s}$ ) and a reference diotic sound were presented in random order, separated by a $500 \mathrm{~ms}$ pause. The task was to indicate whether the first or the second sound was louder, with no other possible option and independently of any other perceived difference, by clicking a button on a MaxMSP graphical user interface using the mouse or keyboard. These instructions were indicated both orally and in written form, and a few trials were presented before the beginning of the test in order to familiarize the subjects with the interface 
and procedure. The test sounds were presented at an initial level of $\pm 10 \mathrm{~dB}$ than the reference sound levels (except for the 30 and 90 phon references, whose test sounds started at +10 and $-10 \mathrm{~dB}$, respectively, in order to avoid extreme levels), and were lowered by a given amount when the subjects judged it louder than the reference, whereas it was increased when the subjects judged it was less loud than the reference. The step size was initially set to $\pm 4 \mathrm{~dB}$, and changed to $\pm 1 \mathrm{~dB}$ after two reversals in the equalization curve (i.e., when the loudness judgment of the subject changed from one trial to another for the same test sound). A total of eight reversals was collected for each test sound, and then the points of subjective equality (PSE) were derived from the means of the levels at the six last reversals. The experiment was split in two sessions, with a 5-min break between them. One of these sessions contained the 30,40 and 50 phon reference stimuli, and the other one contained the $60,70,80$ and 90 phon reference stimuli in order to keep the subject working on the same range of levels during each session. Every subject participated in the two sessions in a random order. In each session, the 12 or 16 adaptive sequences related to the experimental conditions (depending on the session: 2 ITDs, 2 frequencies and 3 or 4 levels) were randomly ordered and interleaved on a trialby-trial basis. Then, each session appeared as a following of unrelated paired comparisons of loudness to the subjects. The subjects sat in an audiometric booth and were told to comfortably place the headphone on their head so that they would not have to replace it during the whole session. A test lasted approximately one hour (20 min for the low-level session and $30 \mathrm{~min}$ for the high-level session, plus the pretest and the break).

\section{RESULTS}

(a)

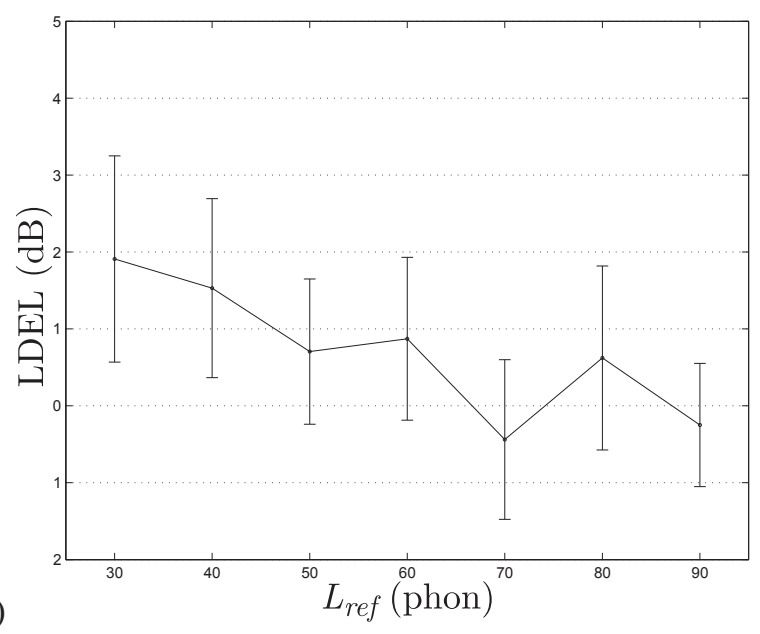

(b)

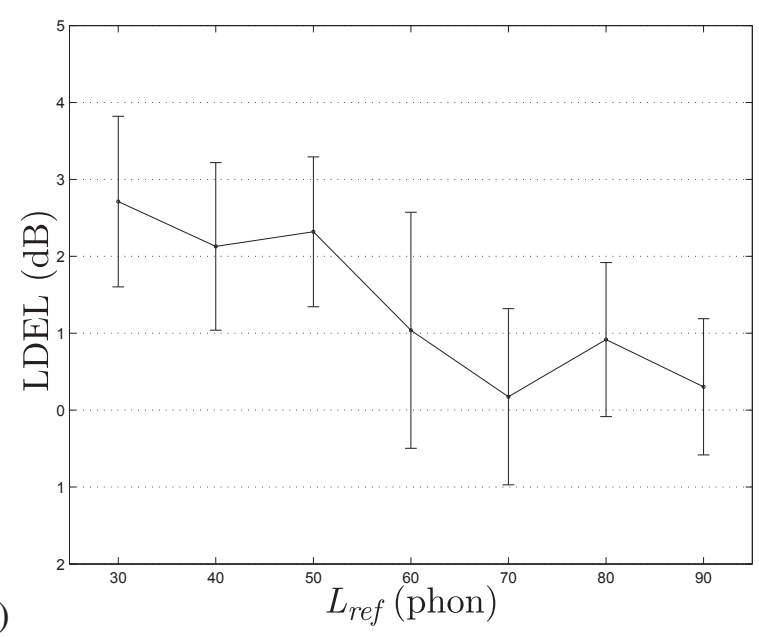

Figure 1: LDEL as a function of reference stimuli level at $100 \mathrm{~Hz}($ a) and $200 \mathrm{~Hz}(\mathrm{~b})$ with $95 \%$ confidence intervals.

The results were presented as level differences for equal loudness (LDEL). A LDEL of $3 \mathrm{~dB}$ meant that the dichotic test sound was perceived $3 \mathrm{~dB}$ louder than its diotic equivalent).

A $t$-test revealed that the LDEL was significantly different from zero at $100 \mathrm{~Hz}$ for the 30 phon $(p=$ $.007)$ and 40 phon $(p=.012)$ stimuli. At $200 \mathrm{~Hz}$, a significant difference was revealed at 30 phon $(p<$ $.001), 40$ phon $(p=.001)$ and 50 phon $(p<.001)$.

The LDEL obtained in the two sessions were then analyzed using a repeated-measures analysis of variance. The effect of level on LDEL was significant at both 100 and $200 \mathrm{~Hz}(F(6,126)=2.665, p=.018$ and $F(4.111,86.329)=3.656, p=.008$, respectively). A Greenhouse-Geisser correction was applied at 
$200 \mathrm{~Hz}$ due to a violation of the sphericity assumption. A post-hoc LSD test revealed no significant differences between the LDEL that were significantly different from zero (i.e., 30 and 40 phon at $100 \mathrm{~Hz}, 30$, 40 and 50 phon at $200 \mathrm{~Hz}$ ). Figure 1 shows that the LDEL tended to decrease with increasing level of the reference stimulus until 70 phon and stopped being significantly different from zero at 50 phon at $100 \mathrm{~Hz}$ and at 60 phon at $200 \mathrm{~Hz}$.

\section{EXPERIMENT 2}

As an increase in directional loudness sensitivity has been observed for low-level pure tones only, it has been hypothesized that this effect could be accounted for by the interactions between these tones and the internal noise. The signal-to-noise ratio is still relatively high at levels where the effect has been observed. Therefore, this experiment was designed in order to check if a noise could affect the loudness of tones at such a low level. An external noise was presented during a loudness matching test in order to decrease the previously described signal-to-noise ratio. The aim of this external noise was to raise the size of the effect in the event of a sufficiently low signal-to-noise ratio. Since the dichotic test sounds were perceived louder than the diotic ones, and since the observed LDEL could be accounted for by differences in interaural correlation between the noise and signal, the external noise was diotic. The procedure was similar to that of the first experiment, split in two sessions depending on the level of the external noise.

\section{A. STIMULI}

Only $200 \mathrm{~Hz}$ sounds were investigated in this experiment. As the effect of ITD on loudness tends to disappear above 50 phon, reference sounds levels were fixed at $30,40,50,60,70$ or 80 phon. Since the aim of the experiment was to check if an external low-level noise could expand the observed effect to the medium-level stimuli, 90 phon reference stimuli weren't tested. The external noise bandwidth was set to one equivalent rectangular bandwidth (ERB) so that all the components of the noise contributed to an efficient masking of the pure tones. This ERB was computed according to the following equation by Glasberg and Moore (1990) :

$$
\mathrm{ERB}_{N}=24.7 \times(4.37 F+1)
$$

with $F=0.2 \mathrm{kHz}$ the center frequency of the ERB and $N$ the number of the ERB. This equation leads to a $46 \mathrm{~Hz}$-wide ERB. A broadband noise with a 10 min duration was generated using MATLAB and band-pass filtered in the frequency domain by setting the amplitude of all frequencies outside the ERB calculated with Eq. (2) to zero, following the procedure of Edmonds and Culling (2009). This 10 min-long, 1 ERB-wide narrow-band noise was then played back and looped online in MaxMSP during the experiment. Noise levels of 10 and 20 phon were chosen in order to test different signal-to-noise ratios, ranging from approximately $9 \mathrm{~dB}$ (between the 30 phon stimuli and the 20 phon noise) to approximately $61 \mathrm{~dB}$ (between the 80 phon stimuli and the 10 phon noise) since the corresponding sound pressure levels for 10 and 20 phon sounds at $200 \mathrm{~Hz}$ are $24.8 \mathrm{~dB}$ SPL and $35.5 \mathrm{~dB}$ SPL, respectively. Before taking part in the experiment, the subjects had to take an audiometric test to measure their hearing threshold for the narrow-band external noise.

\section{B. PROCEDURE}

Twenty-two subjects ( 6 women and 16 men, aged 20 to 25 years) with hearing thresholds better than $10 \mathrm{dBHL}$ participated in the second experiment. 8 of them ( 2 women and 6 men) had participated in the first experiment.

The procedure was the same as that used in Experiment 1. The two sessions (with 10 and 20 phon noises) were randomly ordered, and so were the 12 experimental conditions of each session (2 ITDs, 6 levels). The subjects were told to place the headphones comfortably on their heads at the very beginning of 
the experiment. The background noise was sent through the headphones since then, without the subjects being aware of it. The instructions were given afterwards, both orally and in written form. Then, a pretest of six comparisons including every reference level randomly ordered was presented to the subject in order to familiarize them with the procedure. Since the external background noise was meant to imitate the internal noise at a higher level and to mix with the latter, it was presented from the very beginning of the experiment in order to involve auditory adaptation before the beginning of the loudness matching test. Hellman et al. (1997) have shown that even at low-frequencies, the loudness of long-duration tones decreases sharply in the first $3 \mathrm{~min}$ of presentation, and keeps decreasing more slightly afterwards. Subjects spent approximately 5 min with the headphones on their heads before the beginning of the test. A short break was offered to the subjects between the two sessions. A test lasted approximately one hour, including two 20 min-sessions, 2 pretests and instructions, and the break.

\section{RESULTS}

(a)

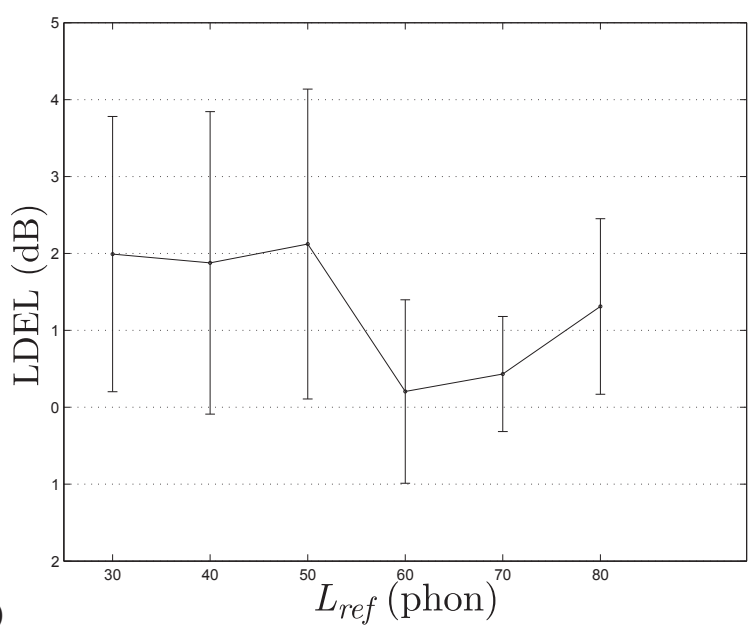

(b)

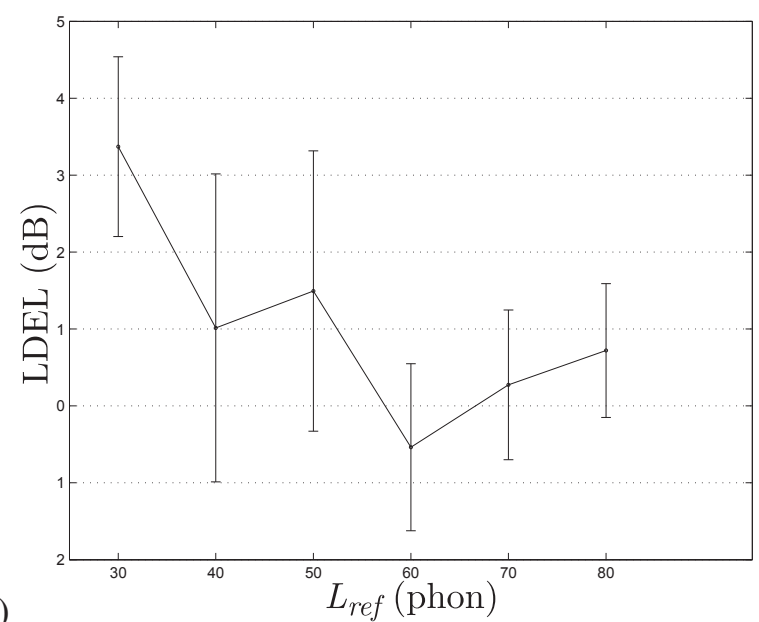

Figure 2: LDEL as a function of reference stimuli level with a 10 phon (a) and 20 phon (b) noise with 95\% confidence intervals.

A $t$-test revealed that the LDEL was significantly different from 0 at 30,50 and 80 phon $(p=.036$, $p=.025$ and $p=.019$, respectively) with the 10 phon noise, and at 30 phon $(p<.001)$ with the 20 phon noise. It can be noticed that Figure 2 (a) (LDEL for $200 \mathrm{~Hz}$ pure tones with a 10 phon background noise) showed almost the same trend as in Figure 1 (b) (LDEL for $200 \mathrm{~Hz}$ pure tones with no background noise), with larger error bars at the lowest levels.

The LDEL obtained in the two sessions were then analyzed through a repeated-measures analysis of variance. The effect of the level on LDEL was significant with the 20 phon noise $(F(3.541,74.355)=$ $4.053, p=.007)$ but not with the 10 phon noise $(F(3.098,65.048)=1.785, p=.157)$. A GreenhouseGeisser correction was used to correct the degree of freedom of these factors. A post-hoc LSD test highlighted that with the 20 phon noise, the LDEL obtained at 30 phon was significantly different from those obtained at higher levels, except 50 phon $(p=.052)$. 


\section{DISCUSSION}

Increases of loudness due to non-zero ITDs were observed for 100 and $200 \mathrm{~Hz}$ pure tones. This effect occurred at low-levels only (30 to 40 or 50 phon, depending on the frequency), and tended to disappear following the same trend at 100 and $200 \mathrm{~Hz}$. These observations confirmed the outcomes from Koehl and Paquier (2015), providing some more data about the evolution of the effect on a large dynamic range. Moreover, the effect was revealed significant on a larger dynamic range at $200 \mathrm{~Hz}$ than at $100 \mathrm{~Hz}$. This effect was significant, since minimum perceptible changes in sound pressure levels were about $1.5 \mathrm{~dB}$ for $100 \mathrm{~Hz}$ pure tones and about $1 \mathrm{~dB}$ for $200 \mathrm{~Hz}$ pure tones at 30 phon, and decrease even more with increasing the level of the stimulus (Fletcher, 1953). At the threshold of hearing, these minimum perceptible changes were larger than the size of the observed effect of the ITD on loudness. This could account for the fact that Koehl et al. (2015) did not find any significant effect of the ITD on loudness at this level.

Since the effect was found significant for low-levels only, the second experiment aimed at verifying if this effect could be a consequence of an extraction of the signal from the internal noise. The signal-to-noise ratio between these tones and the background noise was lowered by adding a low-level external noise. The results of this experiment with a 10 phon noise showed the same trend as the first experiment (see Fig. 1 (b) and Fig. 2 (a)), with far greater error bars for 30, 40 and 50 phon stimuli. The 20 phon background noise led to the same increase of difficulty for the 40 and 50 phon pure tones. However, by comparison with the results in Fig. 1 (b) and Fig. 2 (b), it appears that this noise also contributed to an increase of LDEL for the 30 phon stimuli. This is likely to be accounted for by a sufficiently low signal-to-noise ratio. The results at higher levels still follow the same global trend.

These results highlighted that at high signal-to-noise ratios with a very low level noise (i.e., for 30 to 50 phon stimuli presented upon a 10 phon background noise), the loudness matching task was made more difficult by the noise, whereas at low signal-to-noise ratios (i.e., for the 30 phon pure tone and the 20 phon noise), the noise increased the loudness of the dichotic tones. Since this increase was observed with a noise that was far louder than the internal noise (20 phon) but not with a less loud noise (10 phon), it can be assumed that the internal noise level was not high enough to account for the effect of ITD on loudness.

\section{CONCLUSION}

The results of the first experiment showed that pure tones with ITDs were perceived louder than their diotic equivalents, for low level stimuli up to 40 phon at $100 \mathrm{~Hz}$ and to 50 phon at $200 \mathrm{~Hz}$.

The results of the second experiment clarified the influence of a background noise on this effect. A diotic noise can affect the loudness of pure tones with ITD, in different ways depending on the level of these stimuli. At low signal-to-noise ratios, the presence of the background noise increases the loudness of the dichotic tone. At medium signal-to-noise ratios, it seems that the presence of the low level background noise makes the loudness matching paradigm more difficult.

The signal-to-noise ratio at which the noise begins to affect the loudness of the tones studied in the second experiment lies presumably between 10 and $20 \mathrm{~dB}$. The latter is far lower than the signal-to-noise ratio between the tones of the first experiment and the internal noise, where an effect of ITD on loudness was observed. This result highlights that the increase of loudness for pure tones with ITD couldn't be accounted for by the internal noise alone.

\section{ACKNOWLEDGMENTS}

The authors wish to thank the staff from the "Image \& Son" department of the University of Brest and all the participants of this experiment. 


\section{REFERENCES}

Bernstein, L. R. and Trahiotis, C. (2008), "Binaural signal detection, overall masking level, and masker interaural correlation: Revisiting the internal noise hypothesis," J. Acoust. Soc. Am. 124(6), 3850-3860.

Diercks, K. J. and Jeffress, L. A. (1962), "Interaural phase and the absolute threshold for tone," J. Acoust. Soc. Am. 34(7), 981-984.

Edmonds, B. A. and Culling, J. F. (2009), "Interaural correlation and the binaural summation of loudness," J. Acoust. Soc. Am. 125(6), 3865-3870.

Fletcher, H. (1953), "Minimum perceptible changes in frequency and sound pressure level," in Speech and hearing in communication, 2nd ed (D. Van Nostrand, Oxford, England), vol. x, pp. 144-152.

Glasberg, B. R. and Moore, B. C. J. (1990), "Derivation of auditory filter shapes from notched-noise data," Hear. Res. 47(12), 103-138.

Hellman, R., Mikiewicz, A., and Scharf, B. (1997), "Loudness adaptation and excitation patterns: Effects of frequency and level," J. Acoust. Soc. Am. 101(4), 2176-2185.

Hirsh, I. J. (1948), "The influence of interaural phase on interaural summation and inhibition," J. Acoust. Soc. Am. 20(4), 536-544.

ISO 226 (2003), "Acoustics - Normal equal-loudness-level contours," Standard, International Organization for Standardization, Geneva, Switzerland.

ISO 389-7 (2005), "Acoustics - Reference zero for the calibration of audiometric equipment - Part 7: Reference threshold of hearing under free-field and diffuse-field listening conditions," Standard, International Organization for Standardization, Geneva, Switzerland.

Koehl, V. and Paquier, M. (2015), "Loudness of low-frequency pure tones lateralized by interaural time differences," J. Acoust. Soc. Am. 137(2), 1040-1043.

Koehl, V., Paquier, M., and Hendrickx, E. (2015), "Effects of interaural differences on the loudness of low-frequency pure tones," Acta Acust united Ac 101(6), 1168-1173.

Kuhn, G. F. (1977), "Model for the interaural time differences in the azimuthal plane," J. Acoust. Soc. Am. 62(1), 157-167.

Levitt, H. (1971), “Transformed up-down methods in psychoacoustics,” J. Acoust. Soc. Am. 49(2B), 467477.

Moore, B. C. J. (2012), "Space perception," in An Introduction to the Psychology of Hearing (BRILL, Leiden, Netherlands), chap. 7, pp. 245-250.

Moore, B. C. J. and Glasberg, B. R. (2007), "Modeling binaural loudness," J. Acoust. Soc. Am. 121(3), $1604-1612$.

Moore, B. C. J., Glasberg, B. R., Varathanathan, A., and Schlittenlacher, J. (2016), "A loudness model for time-varying sounds incorporating binaural inhibition," Trends Hear. 20.

Mulligan, B. E., Goodman, L. S., Gleisner, D. P., and Faupel, M. L. (1985), "Steps in loudness summation," J. Acoust. Soc. Am. 77(3), 1141-1154. 
Robinson, D. E. and Jeffress, L. A. (1963), "Effect of varying the interaural noise correlation on the detectability of tonal signals," J. Acoust. Soc. Am. 35(12), 1947-1952.

Robinson, D. W. and Whittle, L. S. (1960), "The loudness of directional sound fields," Acustica 10, 74-80.

Sivonen, V. P. and Ellermeier, W. (2006), "Directional loudness in an anechoic sound field, head-related transfer functions, and binaural summation," J. Acoust. Soc. Am. 119(5), 2965-2980.

Soderquist, D. R. and Shilling, R. D. (1990), “Loudness and the binaural masking level difference," Bull. Psychon. Soc. 28(6), 553-555.

Townsend, T. H. and Goldstein, D. P. (1972), "Suprathreshold binaural unmasking," J. Acoust. Soc. Am. 51(2B), 621-624.

Yost, W. A. (1988), "The masking-level difference and overall masker level: Restating the internal noise hypothesis,” J. Acoust. Soc. Am. 83(4), 1517-1521.

Zahorik, P. and Wightman, F. L. (2001), "Loudness constancy with varying sound source distance," Nat. Neurosci. 4(1), 78-83.

Zwicker, E. and Henning, G. B. (1991), "On the effect of interaural phase differences on loudness," Hear. Res. 53(1), 141-152. 